\title{
Acoustic Emission Characteristics of Different Bamboo and Wood Materials in Bending Failure Process
}

\author{
Ting Wang ${ }^{1}$, Zhiqiang Wang ${ }^{1, *}$, Yin Yang $^{1}$ and Jianhui Zhou ${ }^{2, *}$ \\ ${ }^{1}$ College of Materials Science and Engineering, Nanjing Forestry University, Nanjing, China \\ ${ }^{2}$ School of Engineering, University of Northern British Columbia, Prince George, Canada \\ *Corresponding Authors: Zhiqiang Wang. Email: wangzhiqiang@njfu.edu.cn; Jianhui Zhou. Email: jianhui.zhou@unbc.ca \\ Received: 19 June 2021 Accepted: 03 August 2021
}

\begin{abstract}
The acoustic emission (AE) technique can perform non-destructive monitoring of the internal damage development of bamboo and wood materials. In this experiment, the mechanical properties of different bamboo and wood (bamboo scrimber, bamboo plywood and SPF (Spruce-pine-fir) dimension lumber) during four-point loading tests were compared. The AE activities caused by loadings were investigated through the single parameter analysis and K-means cluster analysis. Results showed that the bending strength of bamboo scrimber was 3.6 times that of bamboo plywood and 2.7 times that of SPF dimension lumber, respectively. Due to the high strength and toughness of bamboo, the AE signals of the two bamboo products were more abundant than those of SPF dimension lumber. However, the $\mathrm{AE}$ evolution trend of the three materials was similar, which all experienced three stages, including gentle period, steady period and steep period, and the area of rupture precursor characteristics could be recognized before the specimen destroyed. Due to the bottom layer was first tensile failure, the main structure of bamboo plywood was destroyed after the stress redistribution. The rupture precursor characteristics could be observed before each peak. Findings put in evidence a good correlation between AE clusters of two bamboo products, while the amplitude and energy of wood signals were lower than those of bamboo. The amplitude and energy from the propagation and aggregation of cracks were greater than those related to micro-cracks initiation.
\end{abstract}

\section{KEYWORDS}

Acoustic emission; bamboo scrimber; bamboo plywood; rupture precursor characteristics; K-means cluster analysis

\section{Introduction}

With the increasingly prominent environmental problems and the declining available resources, the engineered wood products and engineered bamboo products for structures have received more and more attention. Both wood and bamboo are renewable materials with the ability to sequester carbon, which show a better strength-to-weight ratio than steel or concrete [1]. In order to make full use of the abundant bamboo resources, similar to wood, engineered bamboo products have been developed, for example laminated bamboo lumber, bamboo glulam and bamboo scrimber [2]. China is a country rich in bamboo, with the amount and quality of bamboo resources well-known in the world. These engineered bamboo products for constructing buildings or bridges are therefore mainly made in China [1]. 
Compared with wood, bamboo is considered to be the most efficient material in nature, and shows better toughness, less deformation and a shorter growth cycle. Bamboo, as the fastest growing plant, can grow to its full height in 2-4 months with a diurnal growth rate of around 20-100 cm [3]. Meanwhile, studies showed that the flexural ductility, modulus of rupture and modulus of elasticity of bamboo were 3.06 times, 1.72 times and 0.84 times those of wood, respectively [4]. In view of above advantages, it has been widely used in structural projects in China, Japan, Philippines, Indonesia and other Asian countries. In the past few decades, researchers have done lots of work on the mechanical properties of bamboo, which is the main direction of bamboo research. Ribeiro et al. [5] conducted a nondestructive evaluation of the stiffness and bending strength properties of bamboo culms by Stress Wave Timer. Wei et al. [6] carried out the tensile creep and short-term compressive creep tests on bamboo scrimber under different load levels, and proposed the creep prediction models based on Burgers model. Zhang et al. [7] analyzed the influence of height and section size on the axial compressive performance of bamboo short columns, and suggested that the linear regression parameter analysis method could evaluate the impact of size more effectively. Lin et al. [8] suggested using hook joint, which was recommended to be located at the $1 / 4$ length of the sample, and minimize the number of joints. Chen et al. [9] developed a new type of long-span bamboo double-beam component by combining pre-compaction densification process and intermittent hot pressing. Wang et al. [10] found that the number of nodes had a significant influence on the tensile properties of side press-laminated bamboo lumber, while the position of nodes has little influence. Xuan et al. [11] suggested that bamboo nodes would reduce the flexural strength of laminated bamboo lumber unit and had little effect on the bending modulus of elasticity.

As a non-destructive testing technology capable of real-time online dynamic monitoring, acoustic emission (AE) techniques have been widely used in the field of wood materials, mainly focusing on the evaluation of wood mechanical properties, wood machining, and drying detection [12]. As AE technology is very sensitive to the nucleation and expansion of cracks, it can be used to detect the status information of $\mathrm{AE}$ source and evaluate the internal characteristics of material damage and defects. Diakhate et al. [13] studied the crack tip propagation of wood material under laboratory static tests by using Double Cantilever Beam specimens. Rescalvo et al. [14] investigated the relationship between the process of fracture and the spectral response of AE events within poplar wood. During the process of wood drying, AE technology can be used to monitor the AE events inside the wood, so as to control the wood drying defects caused by stress and strain. Schniewind et al. [15] and Lee et al. [16] recommended that identifying key characteristics and respective critical values should be the key to monitor the drying process of wood. Kowalski et al. [17] divided the AE events emitted during convective drying of wood into three characteristic groups and explained the results according to the three stages of wood drying. Some scholars have found that the AE events are related to the cutting parameters, wood species and the state of tool. Aguilera et al. [18] evaluated the relationship between radiata pine with different grain angles and AE events during cutting. Iskra et al. [19] established the relationship between AE signal and feeding speed during machining and developed an automatic feeding control system by setting different speeds. In fact, the application of AE technology in the field of bamboo and wood will contribute to rationally use materials, improve production efficiency and product quality, and ensure the safe use of materials. Though AE technology has been widely used in the field of wood as mentioned above, there is still lack of reports on the application of it in the field of bamboo.

The research work we present here mainly focused on the effect of material kinds on AE signals during the four-point bending tests. The mechanical properties of bamboo scrimber, bamboo plywood and SPF dimension lumber as well as the AE activities caused by loadings were compared. Through AE parameter analysis and K-means cluster analysis, the AE activities were correlated with the loading process, and the $\mathrm{AE}$ signal characteristics of different damage mechanisms were explored. 


\section{Materials and Testing Methods}

\subsection{Material}

Three different bamboo/wood were prepared: bamboo scrimber, bamboo plywood and SPF dimension lumber. Bamboo scrimber specimens were purchased from Chiyu Decoration Materials Co., Ltd., Fujian Province, China. The average density was $1.19 \mathrm{~g} / \mathrm{cm}^{3}$, and average moisture content (MC) was $5.51 \%$. Bamboo plywood specimens were purchased from Guangyu Bamboo Industry Co., Ltd., Zhejiang Province, China. The measured average density was $0.83 \mathrm{~g} / \mathrm{cm}^{3}$, and average MC was $6.88 \%$. SPF dimension lumber specimens, collected from Canada, had the average density of $0.45 \mathrm{~g} / \mathrm{cm}^{3}$ (measured at $13.39 \%$ of MC). According to the Chinese standard GB/T 17657-2013 (Test methods of evaluating the properties of wood-based panels and surface decorated wood-based panels) [20], all of them were processed to the dimensions of $300 \mathrm{~mm}$ (length) $\times 20 \mathrm{~mm}$ (width) $\times 20 \mathrm{~mm}$ (thickness). The groups of bamboo scrimber, bamboo plywood and SPF dimension lumber were recorded as S1-S3 groups, respectively. 12 specimens were prepared for each group.

\subsection{Four-Point Bending Test and AE Instrumentation}

Fig. 1 provides a schematic diagram of the experimental equipment. The four-point bending tests were conducted on a universal testing machine (SHIMADZU AG-X/AG-IC). All of them were loaded to failure at a loading rate $4.0 \mathrm{~mm} / \mathrm{min}$ according to $\mathrm{GB} / \mathrm{T}$ 17657-2013. The tests were monitored by AE technology using PXDAQ24260-2 equipment. Two $150 \mathrm{kHz}$ resonant sensors of type PXR15 (Ra (1) and Ra (2)) with an optimum operating frequency range of $100-400 \mathrm{kHz}$ were arranged on the upper surface of the specimen, $50 \mathrm{~mm}$ away from the end of the specimen. Before the experiments, the appropriate $\mathrm{AE}$ system parameters were adjusted. The $\mathrm{AE}$ acquisition threshold was set to $42 \mathrm{~dB}$ for all specimens for reducing the influence of irrelevant noise. The preamplifier was set to $40 \mathrm{~dB}$, and the sampling frequency of the waveform recording was $1.25 \mathrm{M}$. The value chosen for the high pass of analogue filters was $20 \mathrm{kHz}$, while the low pass was $400 \mathrm{kHz}$. The peak definition time (PDT), hit definition time (HDT), and hit lockout time (HLT) were chosen as 35,150 and $300 \mu \mathrm{s}$, respectively. The universal testing machine and $\mathrm{AE}$ equipment were operated at the same time, until the specimens failed. The load, mid-span deflection and AE events were recorded, and the failure mode was observed.

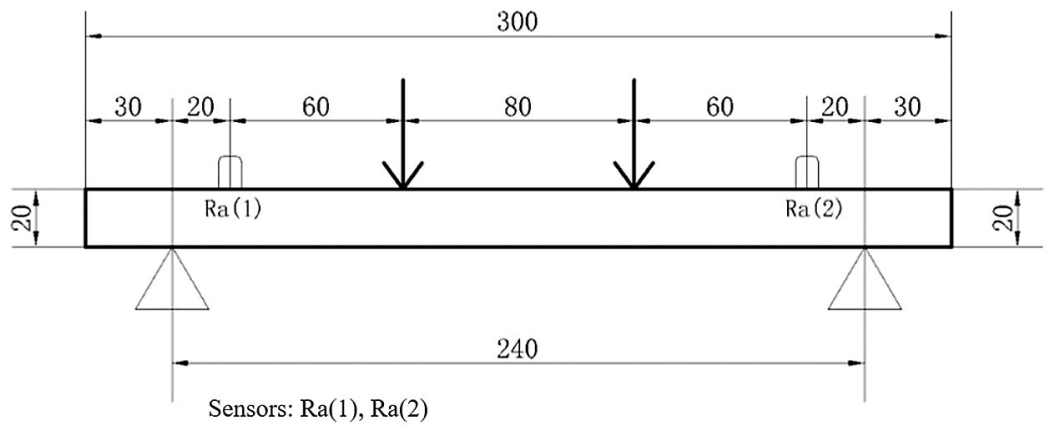

Figure 1: Test configuration and sensors location in four-point bending test (Unit: $\mathrm{mm}$ )

\subsection{Data Analysis}

The specific cluster analysis process used in this paper is referred to the literature [13,21,22]. Firstly, data was standardized by Z-Score and the system clustering was used to construct the decision tree to select the relevant features by SPSS statistical software. Ward's method was used, and the squared Euclidean distance 
was chosen as measurement interval. In the decision tree, the Y-axis and X-axis represented the $\mathrm{AE}$ characteristic parameters and the correlation, respectively. The smaller the value of $\mathrm{X}$-axis, the higher degree of correlation. Then, Silhouette coefficient (SC) index and Davies-Bouldin (DB) index were selected to choose the optimal number of clusters [23,24]. Finally, the K-means method was used to cluster the AE signals, which would be related to the damage mechanisms in the process of bending failure process.

\section{Results and Discussion}

\subsection{Mechanical Properties and Fracture Patterns}

Fig. 2 shows the average middle-span deflection and load diagram of the three. The bending process could be divided into three stages according to the load and middle-span deflection curves. The first stage corresponds to the elastic stage, where the load and middle-span deflection showed a linear relationship. At this time, the specimens just deformed without visible cracks. As the load increased, it entered the elastic-plastic stage with the curves increasing nonlinearly. A few visible micro-cracks began to appear on the surface of the specimens. In the third stage called failure stage, the micro-cracks propagated rapidly until the fiber on the tension side reached the yield limit and then broke. This stage lasted for a short time and was accompanied by obvious sound of destruction. It was worth noting that bamboo plywood showed different trends, which showed two obvious peaks. This was mainly due to the multi-layered structures of bamboo plywood. During the loading process, the top layer of bamboo plywood was compressed and the bottom layer was in tension first. As the load increased, the former caused the local buckling of the top layer, while the latter led to the delamination between bamboo strips layer and the tensile failure of the bottom layer, resulting in the ultimate failure [25]. As shown in the Fig. 3, most final cracked specimens showed damage in the tension zone at the bottom. It was mainly caused by the fiber bundle at the bottom of the middle-span reaching the ultimate tensile strength, and there was no obvious damage at the top, except for the bamboo plywood. It could be seen in Fig. 3 that the top layers of S2 -5 and S2-8 were compressed and sheared, resulting in the separation of bamboo strips layers in pure bending region [25].

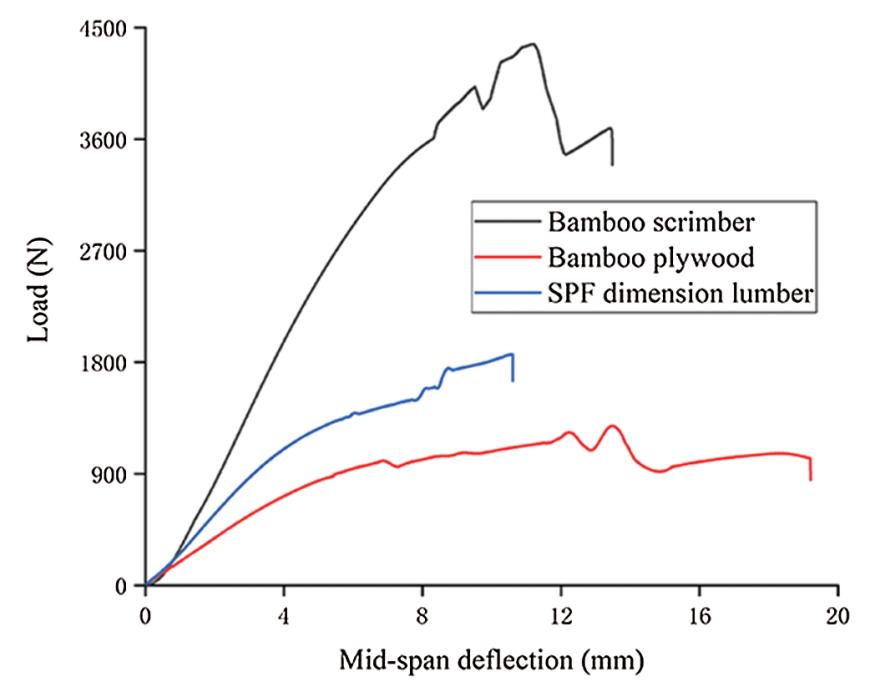

Figure 2: Relation curve between average middle-span deflection and load in bending test 


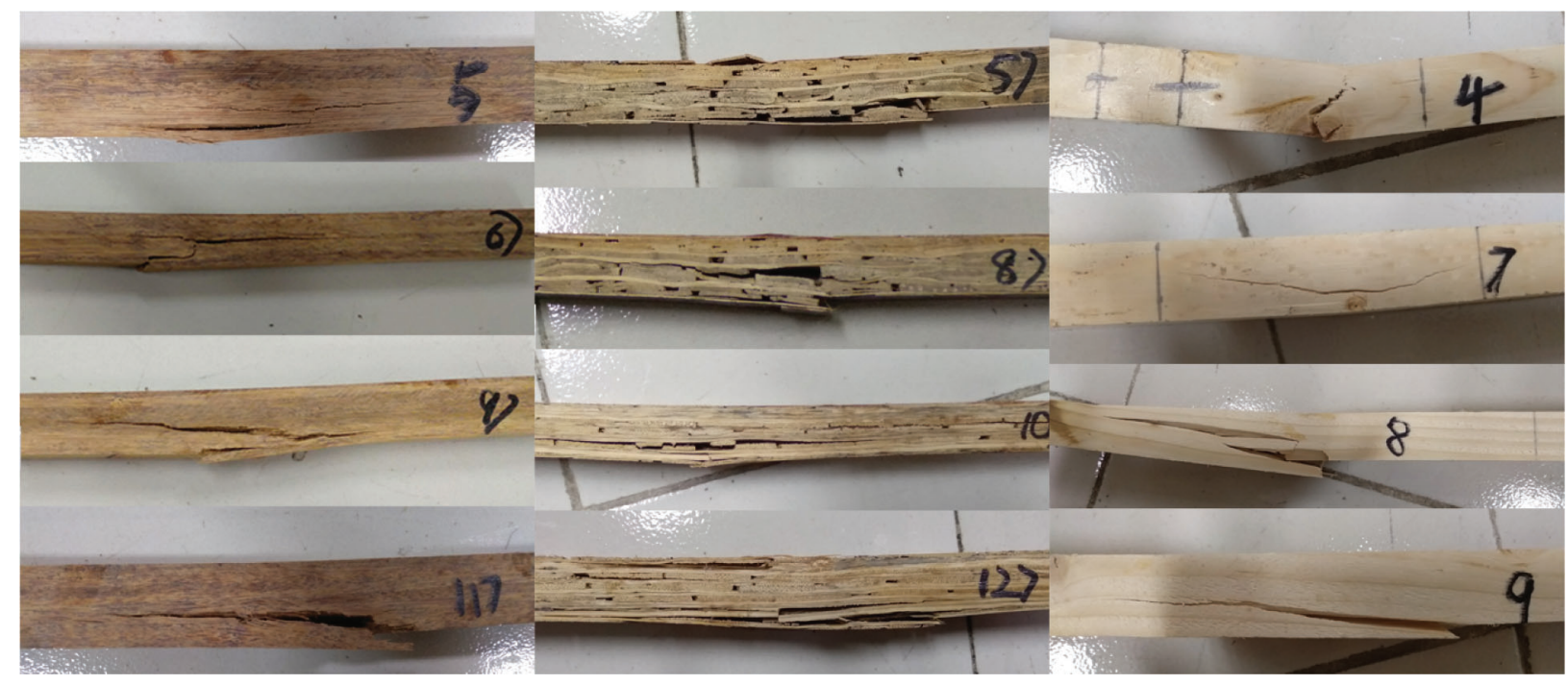

Figure 3: The failure modes of tested specimen (from left to right: bamboo scrimber, bamboo plywood and SPF dimension lumber)

The average values of bending properties of the three groups are given in Tab. 1. It could be seen that the bamboo scrimber had the highest bending strength, which was 3.6 times and 2.7 times that of bamboo plywood and SPF dimension lumber, respectively. The bamboo plywood showed the lowest bending strength, due to the alternation of orient direction in adjacent plies and the gaps between the bamboo strips, which was easy to cause stress concentration under loading.

Table 1: Average value of three groups under four-point bending tests

\begin{tabular}{llll}
\hline Group & $\begin{array}{l}\text { Maximum load/ } \\
\mathrm{N}\end{array}$ & $\begin{array}{l}\text { Maximum mid-span deflection/ } \\
\mathrm{mm}\end{array}$ & $\begin{array}{l}\text { Bending strength/ } \\
\mathrm{MPa}\end{array}$ \\
\hline Bamboo scrimber (S1) & $4050(11.01)$ & $10.52(13.86)$ & $121.50(18.9)$ \\
Bamboo plywood (S2) & $1109(24.85)$ & $12.73(25.82)$ & $33.29(11.7)$ \\
SPF dimension lumber & $1464(13.84)$ & $7.83(19.31)$ & $43.93(8.6)$ \\
(S3) & & & \\
\hline
\end{tabular}

Note: In parentheses is the coefficient of variation, \%.

\subsection{Acoustic Emission Activity}

The AE average energy and counts of three groups are compared, as shown in Fig. 4. Due to the high strength and toughness of bamboo, the AE signals of the two bamboo materials were more abundant than those of SPF dimension lumber. Among the three, bamboo plywood specimens produced the most AE signals, followed by bamboo scrimber, and SPF dimension lumber was the least. The energy and counts produced by bamboo plywood were 9.1 times and 6.7 times that of SPF dimension lumber, while 2.0 times and 2.7 times that of bamboo scrimber, respectively. The results could be due to the physical and mechanical properties of bamboo, and the delamination failure between the bamboo layers during 
loading. When the specimen fractured under bending load, the multi-layer interface would undergo delamination and cracking, which caused more energy to be absorbed and released [26].

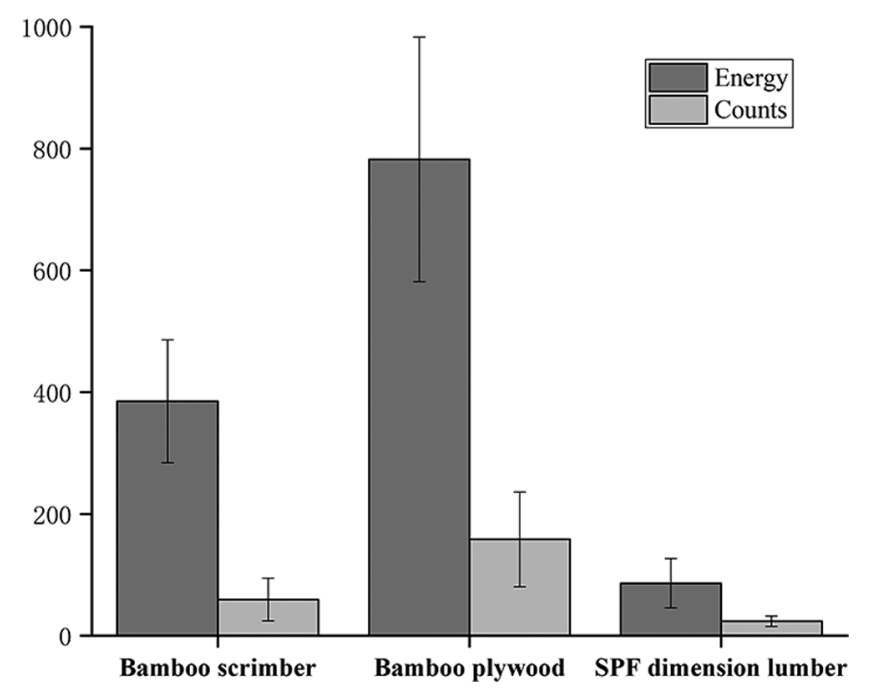

Figure 4: Comparison of the average AE response of different groups

The process of specimens being damaged by load includes the process of energy absorption and energy release. The release of energy corresponds to the rupture of the specimen. Fig. 5 reveals the relationship between AE energy, cumulative energy, and stress vs. time. The results showed that the energy and accumulated energy could be divided into three stages with the loading process: gentle period, steady period and steep period [27]. Each period could correspond to the three loading stages in Section 3.1. In the initial gentle period corresponding to the elastic stage, there was little energy released with a large amount of energy absorption. With the increase of load, a small amount of micro-cracks began to occur inside the specimen, which means that it has entered into the steady period characterized by a steady increase in energy release. The specimen in the steep period was under high stress, when the wood/ bamboo fiber bundles were broken and pulled out, and a large number of micro-cracks initiated and propagated into macro-cracks, resulting in the final failure of the specimen. At this fracture stage, a large amount of high-energy was released rapidly, which was manifested by the sharp increase in the slope of the cumulative energy curve and the emergence of a limit value. At the end of the cumulative energy curve, there would be a short period of stability with the slope of the curve close to zero. This may be caused by the release of part of residual energy after specimen failure.

Among the three groups, SPF dimension lumber showed a more gentle stepped growth during the steep period, while the bamboo materials surged. It may be attributed to that the cracks of bamboo during flexure propagate in a tortuous manner, leading to dramatic energy absorption [28]. There were some obvious steps could be observed on the cumulative energy curve before the failure of bamboo plywood, which could correspond to the delamination failure between the strips and ruptures of the different layers [29,30]. Moreover, it can be found that there were two flat periods at the end of S2-11 (Fig. 5B). The first flat period was attributed to the tensile failure of bottom layer. After that, the stress was redistributed, which resulted in the final failure with release of residual stress, expressed in the form of the second flat period. 
JRM, 2022, vol.10, no.2
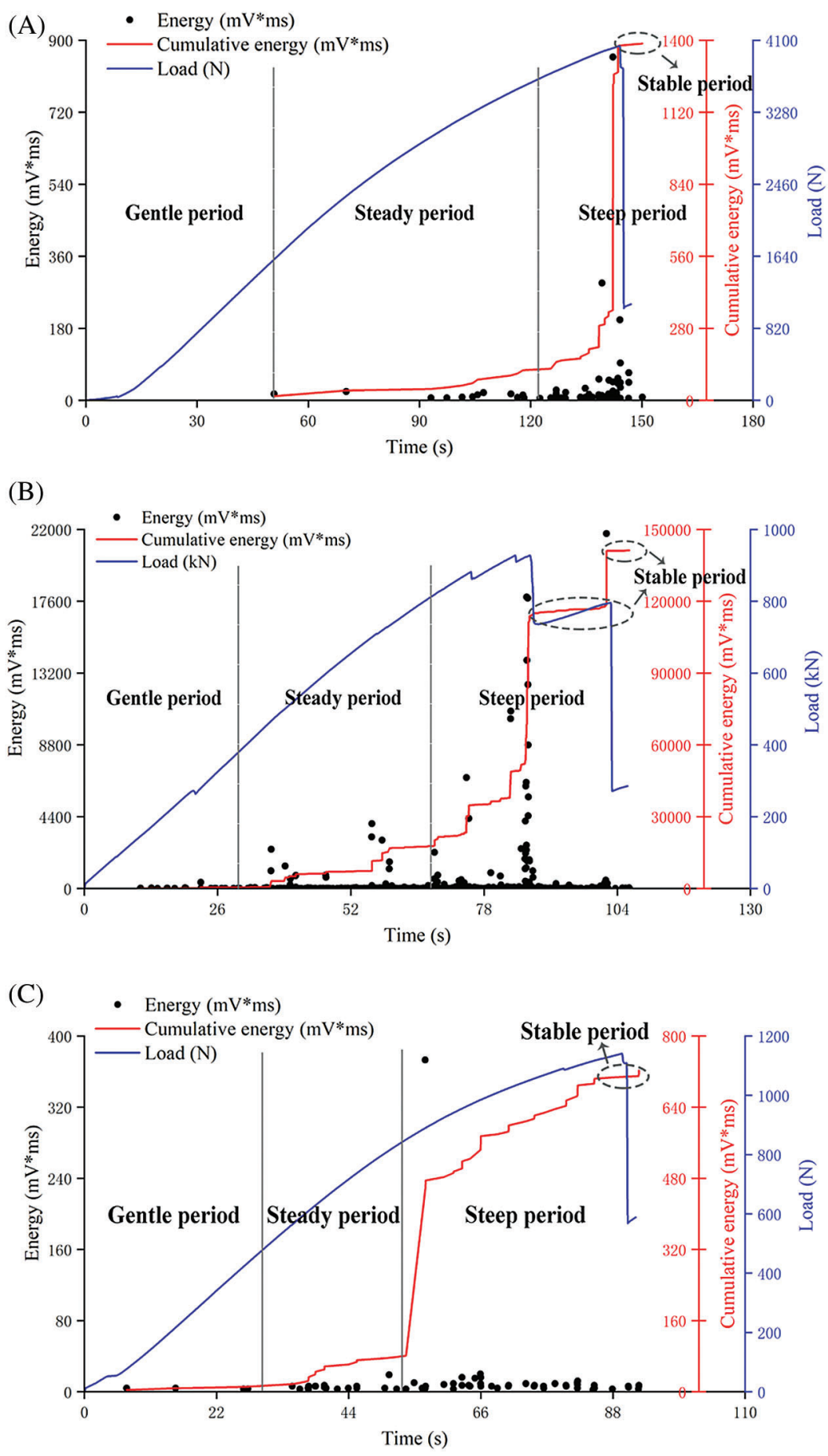

Figure 5: AE energy-cumulative energy-stress-time curve of three representative specimens (A) S1-3 (B) S2-11 (C) S3-6 
Fig. 6 shows the relationship between counts, cumulative counts, and stress vs. time. Through analysis, it could be found that the development trend of counts was similar to that of energy. The counts were almost undetectable in the first period. As the load increased, the counts started to appear and maintained a certain level. The sudden increase of counts in the third period indicated that AE was extremely active and the development of cracks was extremely rapid. The rupture precursor recognition characteristics were that the counts keep fluctuating within a medium to high level with an obvious aggregation, but suddenly become gentle when the stress was the highest [27]. In the areas of rupture precursor characteristics in Fig. 6, the low counts with less number represented the initiation and propagation of a large number of micro-cracks, while the high counts with more number represented the micro-cracks propagated and coalesced into large cracks. Owing to the excellent toughness of bamboo, the areas of rupture precursor characteristics of bamboo scrimber S1-3 (Fig. 6A) and bamboo plywood S2-11 (Fig. 6B) were more obvious than that of SPF dimension lumber S3-6 (Fig. 6C). The failure process of S3-6 was relatively gentle, without obvious concentration of counts before failure. In addition, S2-11 could observe obvious failure precursors before the two peaks of the failure.

The frequency of counts is positively correlated with the activity of AE signals, and also closely correlated with the energy, both of which can establish a qualitative relationship with the damage stage of the specimen. Generally speaking, the damage process of three groups can be separated into two periods according to the AE signals: damage accumulation period and failure period. The former period represented the micro-crack initiation, in which the energy was released steadily and counts maintained a certain level. The micro-cracks aggregated into large cracks in the latter period, leading to the final damage. In this period, the energy was released rapidly and in large amounts, and the rupture precursor characteristics could be recognized according to counts.

\subsection{Cluster Analysis of AE Signals}

The AE signals generated during the four-point bending process were analyzed by K-means cluster analysis, the detailed analysis process of which was described in Section 2.3. The cluster analysis of AE signals was summarized in Figs. 7 and 8.

Fig. 7A shows the evaluation of the correlation between the eight AE parameters. The smaller the value of $\mathrm{X}$-axis representing the correlation degree between characteristic parameters, the higher degree of correlation. It was obvious in Fig. 7A that amplitude and counts, energy and duration had a high correlation, rise time and peak count, average frequency and peak frequency were highly correlated. Therefore, the characteristic parameters with a correlation coefficient greater than 5 were selected as characteristic parameters of S1-3, namely, amplitude, rise time and average frequency. Eight characteristic parameters of S2-11 and S3-6 could be divided into three and four groups through the same method. The characteristic parameters of S2-11 were counts, rise time, amplitude and average frequency, while those of S3-6 were the same as those of S2-11. The choice of the number of clusters based on a high SC index and low DB index can be seen from Fig. 7B. The optimal number of clusters of S1-3 and S2-11 was 3, and the optimal number of clusters of S3-6 was 2.

Fig. 8B shows the cluster analysis results of the AE signals of S2-11 based on the K-means algorithm. Cluster 1 accounted for $16.7 \%$ of the AE signals, with the average amplitude about $57 \mathrm{~dB}$ and the average energy about $29 \mathrm{mV} \cdot \mathrm{ms}$. The quantity of Cluster 2 was relatively small, about $6.6 \%$. This cluster occupied most of the low part of amplitude and energy, and distributed over the whole loading process. Cluster 3 accounted for $76.7 \%$ of the signals, with high amplitude and energy, the average energy of which was 3.8 times that of Cluster 1 and 15.7 times that of Cluster 2. Moreover, Cluster 3 concentrated in the fracture stage, which had obvious AE signals surge in the time of two breaks of specimen. 
JRM, 2022, vol.10, no.2

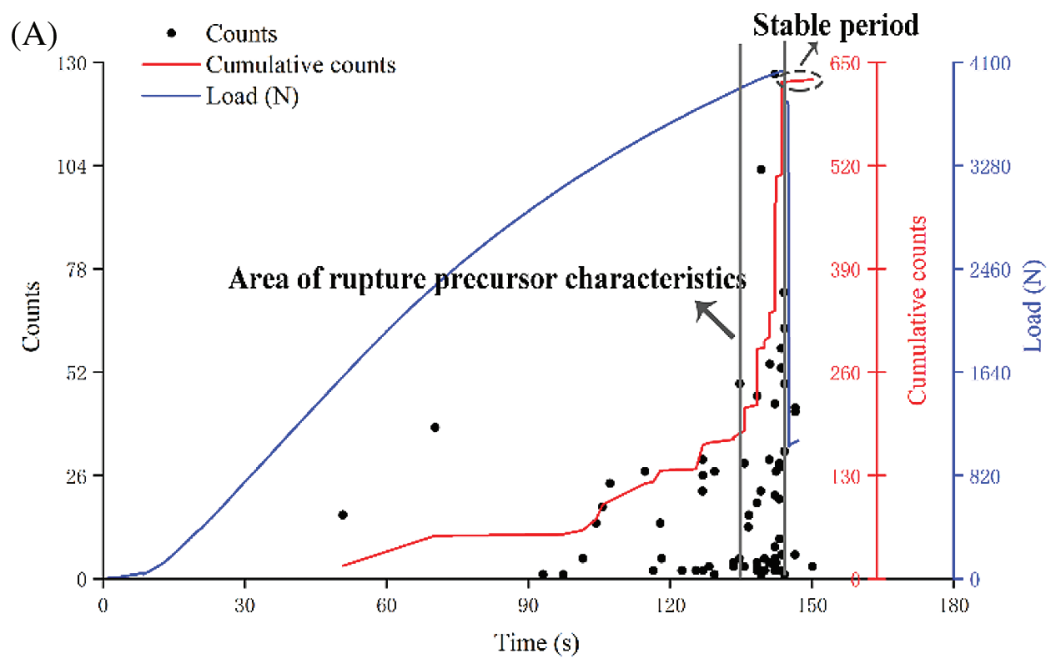

(B)

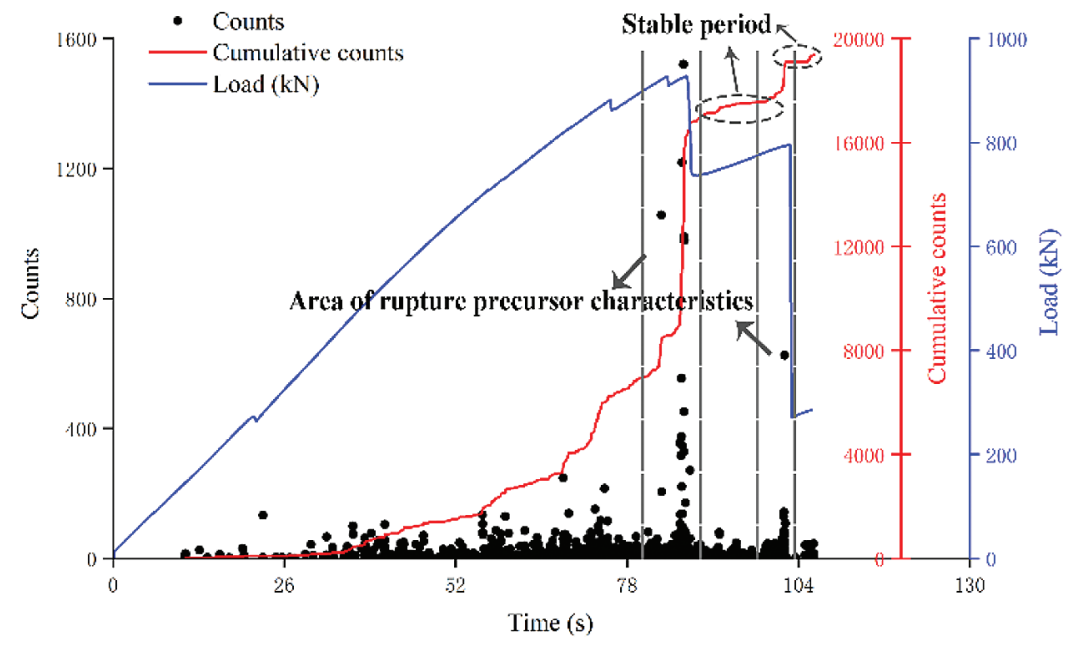

(C)

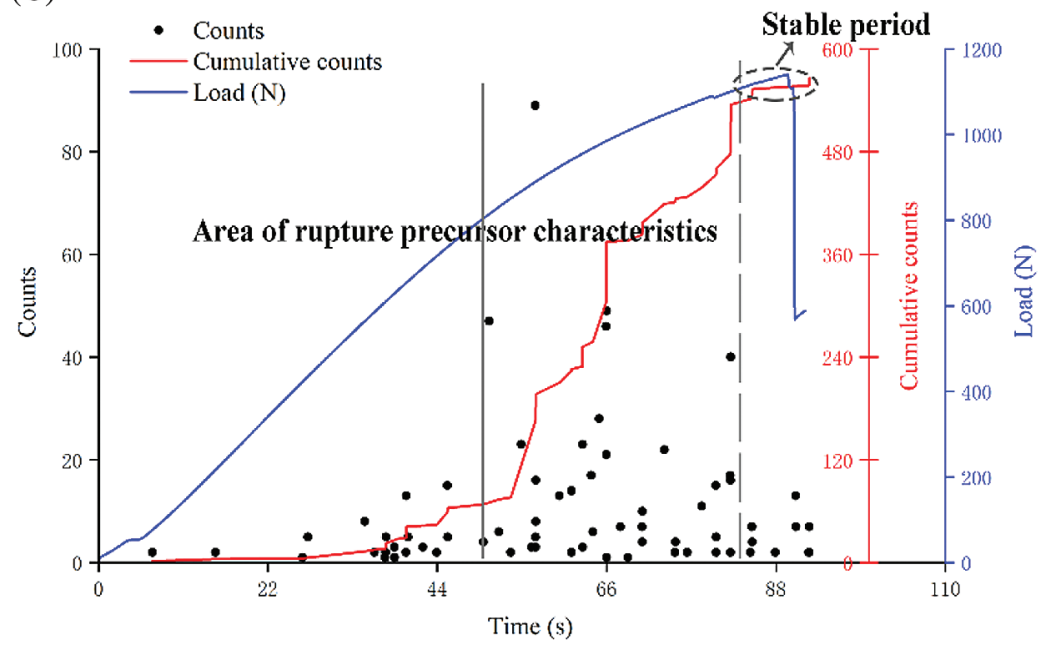

Figure 6: Counts rate-cumulative counts-stress-time curve of three representative specimens (A) S1-3 (B) S2-11 (C) S3-6 

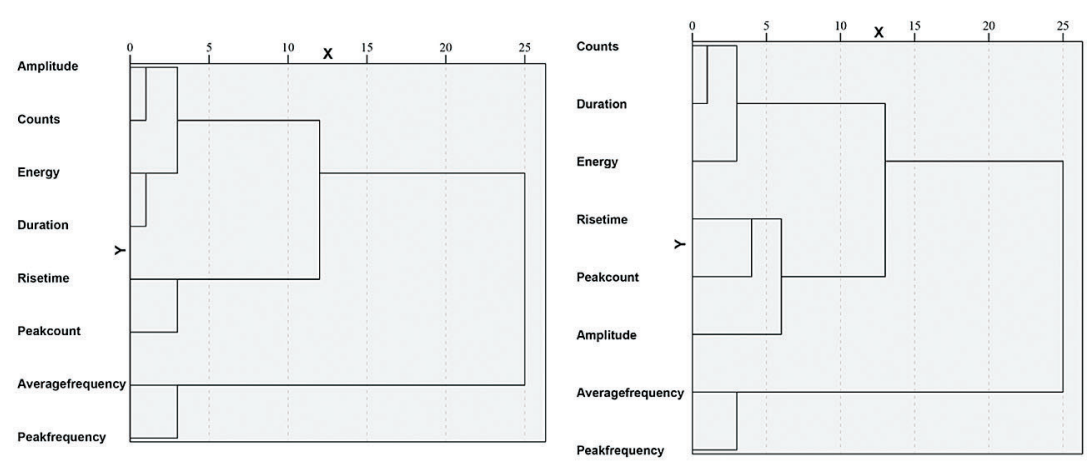

(A)
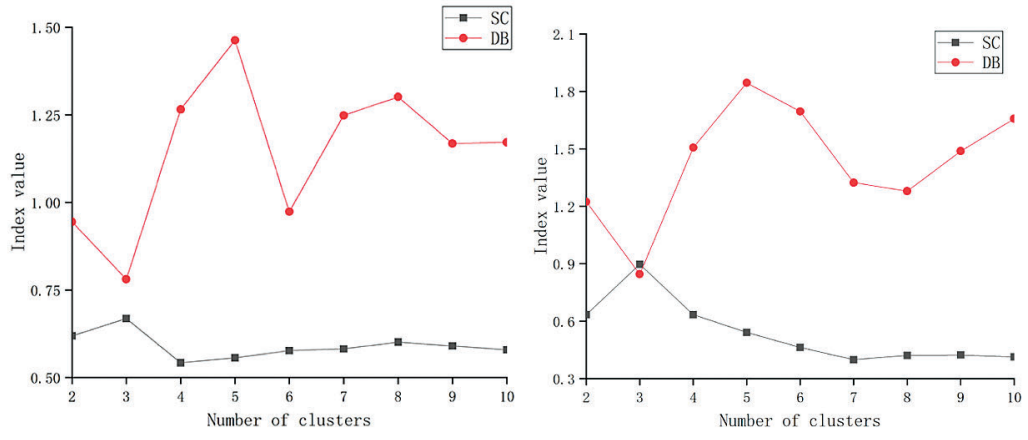

(B)
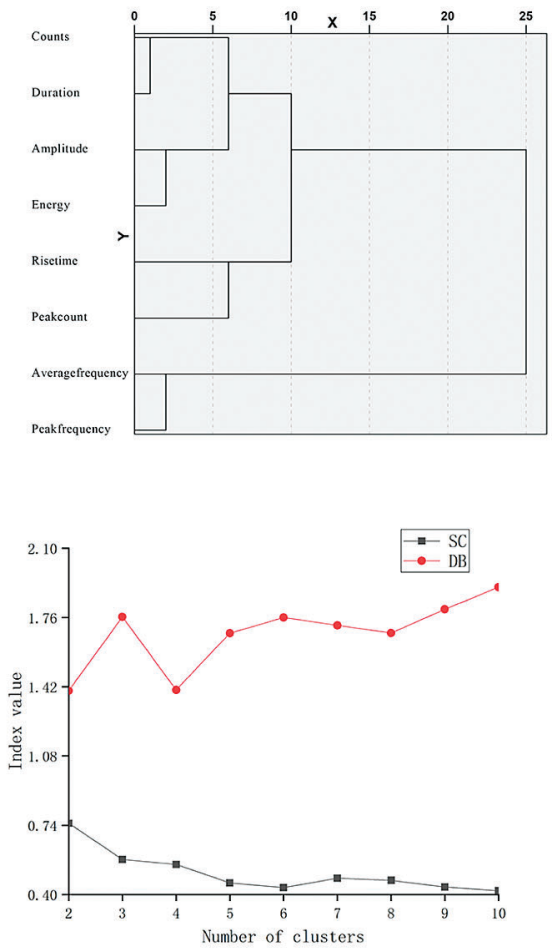

Figure 7: Cluster analysis (from left to right: $\mathrm{S} 1-3, \mathrm{~S} 2-11, \mathrm{~S} 3-6$ ) (A) AE parameter spectrum (B) Polymerization coefficient

In S2-11, the tensile failure of bottom bamboo plywood layer first appeared, and then the cracks extended upward, resulting in a large crack in the middle of the specimen, the length of which was about $1 / 5$ of the length specimen. Analyzing the clustered AE signals with the damage process of the specimen, the results showed that each cluster could be associated with a specific damage mechanism. Chen et al. [31] pointed out three peak frequency bands could correspond to the different fracture behavior modes of bamboo, namely, $80-130 \mathrm{kHz}$ stands for the failure of parenchyma cells, 250-275 kHz corresponds to fiber dissociation and $280-330 \mathrm{kHz}$ corresponds to the bamboo fiber breakage. Clusters 2 and 3 were similar in the peak frequency band, which were $55-312 \mathrm{kHz}$ and $60-312 \mathrm{kHz}$, respectively. Considering that there was a significant aggregation of $\mathrm{AE}$ signals in both areas of rupture precursor characteristics, and it was coinciding with the generation time of the crack sound. Hence, Cluster 3 might result from the propagation and aggregation of micro-cracks. While Cluster 2 could be attributed to the initiation of micro-cracks, which contained most amplitude lower than $60 \mathrm{~dB}$ and showed a small aggregation at the first peak. The cluster 1 might come from the delamination behavior.

The AE signals of S1-3 and S3-6 were analyzed by the same clustering method as S2-11. Figs. 8A and $8 \mathrm{C}$ show the cluster analysis results of them, respectively. Taking into account the AE parameters, there was a clear difference in the $\mathrm{AE}$ characteristics parameters of different specimens, the average $\mathrm{AE}$ value of each cluster of bamboo products was greater than that of SPF dimension lumber. Two bamboo products showed consistency in the following aspects. The average amplitude of Cluster 3 of S1-3 and Cluster 1 of S2-11 were both about $57 \mathrm{~dB}$, with the average counts about 18 . The average amplitude of 
Cluster 2 of S1-3 and S2-11 were about $50 \mathrm{~dB}$, with the average energy about $7.5 \mathrm{mV} \cdot \mathrm{ms}$ and the average counts about 4 . The average energy of Cluster 1 of S1-3 and Cluster 3 of S2-11were about $110 \mathrm{mV} \cdot \mathrm{ms}$. According to the analysis in the previous paragraph, Cluster 2 of S1-3 was related to the micro-cracks initiation, Cluster 3 was related to the delamination of glue line, and Cluster 1 was related to the propagation and aggregation of cracks. Cluster 2 of S3-6 corresponded to the generation of micro-cracks, while Cluster 1 was related to the macro fracture of wood.

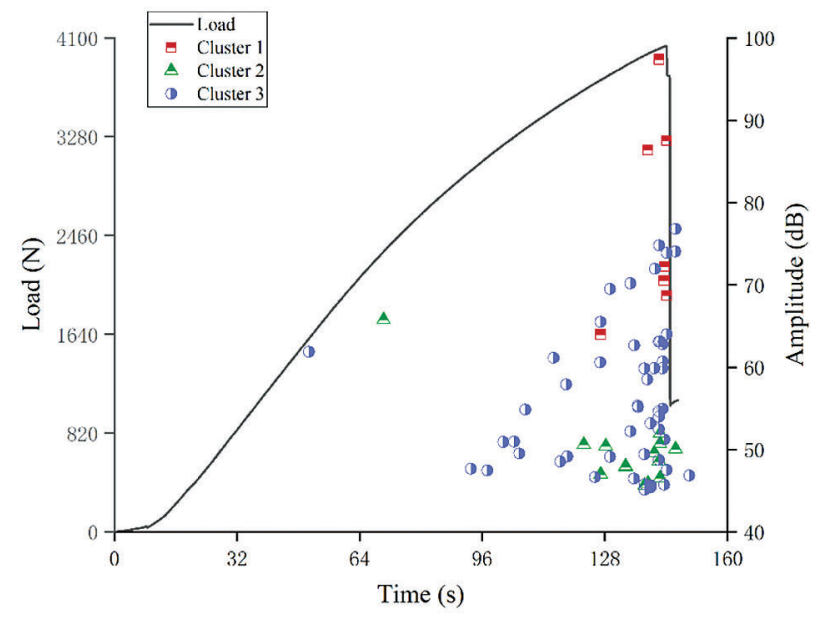

(A)

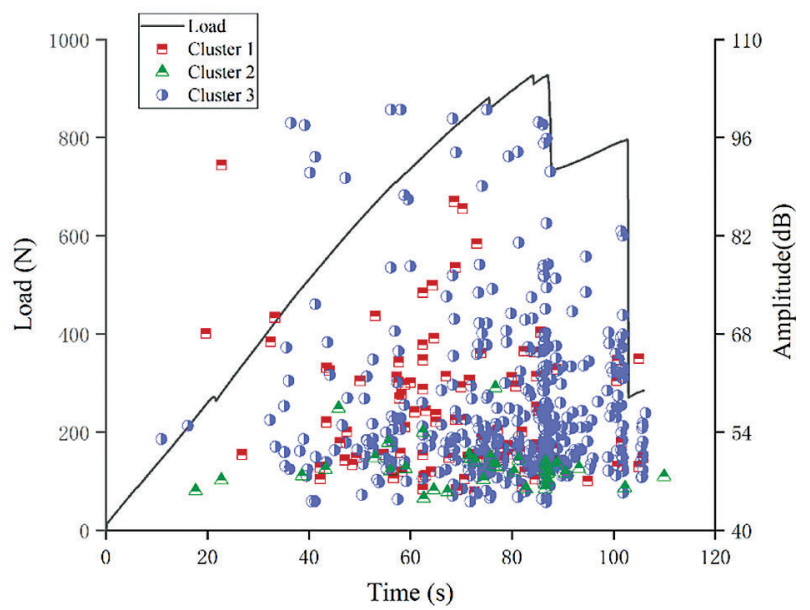

(B)

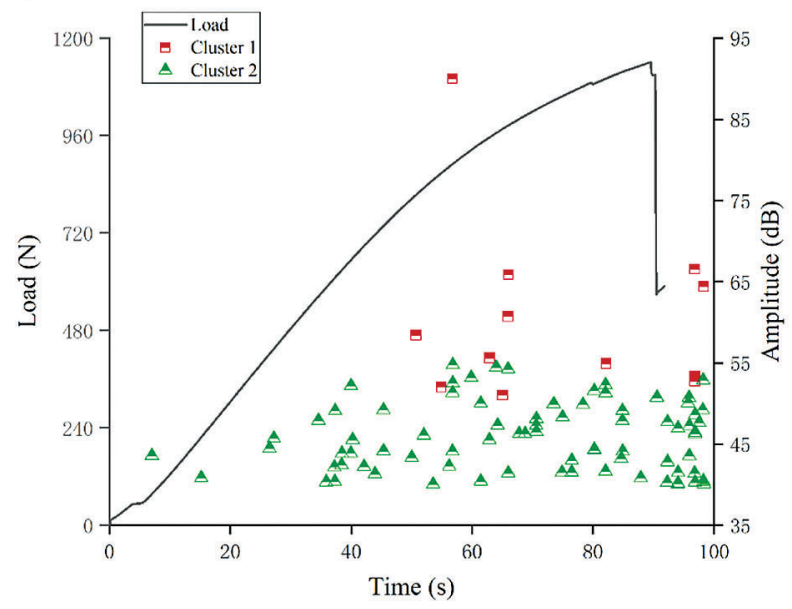

(C)

Figure 8: AE activities for three representative specimens (A) S1-3 (B) S2-11 (C) S3-6

By comparing the clustering results of AE signals of three specimens, the AE signals could be classified into two types: the main AE signals with middle amplitude and the secondary AE signals with high amplitude. Statistical analysis of clustering features is shown in Tab. 2. The amplitude range of the main AE signals was concentrated within $75 \mathrm{~dB}$, with low energy. These AE signals might be caused by the accumulation of internal damage. The crack propagation was accompanied by the continuous release of accumulated energy, leading to the secondary AE signals. All amplitudes greater than $90 \mathrm{~dB}$ were included in the secondary signals, with the energy much higher than that of the main AE signals. Due to the large number of delamination failures of bamboo plywood, the proportion of secondary AE signals was higher than that of main AE signals. 
Table 2: Statistical analysis of clustering features

\begin{tabular}{llllllll}
\hline Group & \multicolumn{3}{c}{ Main AE signals } & & \multicolumn{3}{c}{ Secondary AE signals } \\
\cline { 2 - 3 } & $\begin{array}{l}\text { Percentage } \\
(\%)\end{array}$ & $\begin{array}{l}\text { Amplitude } \\
(\mathrm{dB})\end{array}$ & $\begin{array}{l}\text { Energy } \\
(\mathrm{mV} \cdot \mathrm{ms})\end{array}$ & & $\begin{array}{l}\text { Percentage } \\
(\%)\end{array}$ & $\begin{array}{l}\text { Amplitude } \\
(\mathrm{dB})\end{array}$ & $\begin{array}{l}\text { Energy } \\
(\mathrm{mV} \cdot \mathrm{ms})\end{array}$ \\
\hline S1-3 & 90.4 & $45-88$ & $5-93$ & & 9.6 & $64-97$ & $26-858$ \\
S2-11 & 23.3 & $44-87$ & $5-376$ & & 76.7 & $44-100$ & $5-4284$ \\
S3-6 & 85.6 & $40-55$ & $2-21$ & & 14.4 & $50-90$ & $10-373$ \\
\hline
\end{tabular}

\section{Conclusion}

In this study, four-point loading tests were carried out on bamboo scrimber, bamboo plywood and SPF dimension lumber to compare the mechanical properties of different bamboo and wood as well as the AE activities caused by bending. Through AE parameter analysis and cluster analysis, the AE activities were correlated with the loading process, and the AE signal characteristics of different damage mechanisms were explored. The main conclusions were summarized as follows:

1. The bending strength of bamboo scrimber was the highest, 3.6 times that of bamboo plywood and 2.7 times that of SPF dimension lumber, respectively. The bending process could be divided into three stages: elastic stage, elastic-plastic stage and failure stage. Bamboo plywood had two peaks at the fracture stage. The first peak corresponded to the tensile failure of bottom layer, while the second one corresponded to the final failure of the specimen.

2. Due to the high strength and toughness of bamboo, the AE signals of the two bamboo products were more abundant than those of SPF dimension lumber. Among them, the average AE signals of bamboo plywood were the highest, which should be attributed to the large number of the delamination failure between the bamboo layers during loading.

3. The energy release process of all specimens has gone through three periods: gentle period, steady period and steep period. Due to the release of part of the residual energy, there was a flat period at the end. For bamboo plywood, there were two flat periods due to the existing two breaks.

4. The development trend of counts was similar to that of energy, while the area of rupture precursor characteristics could be recognized before the specimen failed. In this region, the counts fluctuated at a medium to high level, the ratio of which was much higher than any previous stage. The rupture precursor characteristics could be observed before each peak of bamboo plywood.

5. By comparing the clustering results, the clusters of the two bamboo products showed a high correlation, while the amplitude and energy of wood signals were lower than those of bamboo. The amplitude and energy from the propagation and aggregation of cracks were greater than those related to micro-cracks initiation.

Funding Statement: This paper was supported in part by Project funded by the National Natural Science Foundation of China (Grant Nos. 32071700 and 31570559).

Conflicts of Interest: The authors declare that they have no conflicts of interest to report regarding the present study.

\section{References}

1. Sun, X. F., He, M. J., Li, Z. (2020). Novel engineered wood and bamboo composites for structural applications: State-of-art of manufacturing technology and mechanical performance evaluation. Construction and Building Materials, 249(6780), 118751. DOI 10.1016/j.conbuildmat.2020.118751. 
JRM, 2022, vol.10, no.2

2. Wang, Z. Y., Wei, Y., Li, N., Zhao, K., Ding, M. M. (2020). Flexural behavior of bamboo-concrete composite beams with perforated steel plate connections. Journal of Wood Science, 66(4), 1-20. DOI 10.1186/s10086020-1854-9.

3. Liese, W. (1987). Research on bamboo. Wood Science and Technology, 21(3), 189-209. DOI 10.1007/ BF00351391.

4. Chen, M. L., Ye, L., Li, H., Wang, G., Chen, Q. et al. (2020). Flexural strength and ductility of moso bamboo. Construction and Building Materials, 246(2), 118418. DOI 10.1016/j.conbuildmat.2020.118418.

5. Ribeiro, R. A. S., Ribeiro, M. G. S., Miranda, I. P. A. (2017). Bending strength and nondestructive evaluation of structural bamboo. Construction and Building Materials, 146(1), 38-42. DOI 10.1016/j.conbuildmat.2017.04.074.

6. Wei, Y., Zhao, K. P., Hang, C., Chen, S., Ding, M. M. (2020). Experimental study on the creep behavior of bamboo scrimber. Journal of Renewable Materials, 8(3), 251-273. DOI 10.32604/jrm.2020.08779.

7. Zhang, H., Li, H. T., Hong, C. K., Xiong, Z. H., Lorenzo, R. et al. (2021). Size effect on the compressive strength of laminated bamboo lumber. Journal of Materials in Civil Engineering ASCE, 33(7), 4021161. DOI 10.1061/ (ASCE)MT.1943-5533.0003776.

8. Lin, Q. Q., Huang, Y. X., Li, X. D., Yu, W. J. (2020). Effects of shape, location and quantity of the joint on bending properties of laminated bamboo lumber. Construction and Building Materials, 230(7), 117023. DOI 10.1016/j. conbuildmat.2019.117023.

9. Chen, F. M., Jiang, Z. H., Wang, G., Li, H. D., Simth, L. M. et al. (2016). The bending properties of bamboo bundle laminated veneer lumber (BLVL) double beams. Construction and Building Materials, 119(3), 145-151. DOI 10.1016/j.conbuildmat.2016.03.114.

10. Wang, Z., Li, H. T., Yang, D., Xiong, Z. H., Sayed, U. et al. (2021). Bamboo node effect on the tensile properties of side press-laminated bamboo lumber. Wood Science and Technology, 55(1), 195-214. DOI 10.1007/s00226-02001251-9.

11. Xuan, Y. W., Li, H. T., Bei, Z. M., Xiong, Z. H., Lorenzo, R. et al. (2021). Nodes effect on the bending performance of laminated bamboo lumber unit. Journal of Renewable Materials, 9(6), 1143-1156. DOI 10.32604/ jrm.2021.015292.

12. Ritschel, F., Zhou, Y., Brunner, A. J., Fillbrandt, T., Niemz, P. (2014). Acoustic emission analysis of industrial plywood materials exposed to destructive tensile load. Wood Science and Technology, 48(3), 611-631. DOI 10.1007/s00226-014-0628-1.

13. Diakhate, M., Bastidas-Arteaga, E., Pitti, R. M., Schoefs, F. (2017). Cluster analysis of acoustic emission activity within wood material: Towards a real-time monitoring of crack tip propagation. Engineering Fracture Mechanics, 180(1), 254-267. DOI 10.1016/j.engfracmech.2017.06.006.

14. Rescalvo, F. J., Morillas, L., Valverde-Palacios, I., Gallego, A. (2020). Acoustic emission in I-214 poplar wood under compressive loading. European Journal of Wood and Wood Products, 78(1), 723-732. DOI 10.1007/ s00107-020-01536-7.

15. Schniewind, A. P., Quarles, S. L., Lee, S. H. (1996). Wood fracture, acoustic emission, and the drying process Part 1. Acoustic emission associated with fracture. Wood Science and Technology, 30(4), 273-281. DOI 10.1007/ BF00229350.

16. Lee, S. H., Quarles, S. L., Schniewind, A. P. (1996). Wood fracture, acoustic emission, and the drying process Part 2. Acoustic emission pattern recognition analysis. Wood Science and Technology, 30(4), 283-292. DOI 10.1007/ BF00229352.

17. Kowalski, S. J., Molinski, W., Musielak, G. (2004). The identification of fracture in dried wood based on theoretical modelling and acoustic emission. Wood Science and Technology, 38(1), 35-52. DOI 10.1007/ s00226-003-0211-7.

18. Aguilera, A., Vega, M., Méausoone, P. (2007). Effects of grain angle on the amplitudes of acoustic emission and surface roughness in wood machining. Wood Science and Technology, 41(4), 373-381. DOI 10.1007/s00226-0060117-2.

19. Iskra, P., Tanaka, C. (2006). A comparison of selected acoustic signal analysis techniques to evaluate wood surface roughness produced during routing. Wood Science and Technology, 40(3), 247-259. DOI 10.1007/s00226-005-0059-0. 
20. GB/T 17657 (2013). Test methods of evaluating the properties of wood-based panels and surface decorated woodbased panels. Chinese National Standardization Management Committee, China. https://scholar.google.com/ scholar?hl=zh-CN\&as_sdt=0\%2C5\&q=GB\%2FT $+17657 \& b \operatorname{tnG}=\# d=g$ s_qabs\&u= $\% 23 \mathrm{p} \% 3 \mathrm{DGanWks} \_1$ sk4J.

21. Gutkin, R., Green, C. J., Vangrattanachai, S., Pinho, S. T., Robinson, P. et al. (2011). On acoustic emission for failure investigation in CFRP: Pattern recognition and peak frequency analyses. Mechanical Systems and Signal Processing, 25(4), 1393-1407. DOI 10.1016/j.ymssp.2010.11.014.

22. Perrin, M., Yahyaoui, I., Gong, X. J. (2019). Acoustic monitoring of timber structures: Influence of wood species under bending loading. Construction and Building Materials, 208(1), 125-134. DOI 10.1016/j.conbuildmat.2019.02.175.

23. Maulik, U., Bandyopadhyay, S. (2002). Performance evaluation of some clustering algorithms and validity indices. Journal of Intelligent Systems, 24(12), 1650-1654. DOI 10.1109/TPAMI.2002.1114856.

24. Li, L., Lomov, S. V., Yan, X., Carvelli, V. (2014). Cluster analysis of acoustic emission signals for 2D and 3D woven glass/epoxy composites. Composite Structures, 116(1), 286-299. DOI 10.1016/j.compstruct.2014.05.023.

25. Darzi, S., Karampour, H., Bailleres, H., Gilbert, B. P., McGavin, R. L. (2020). Experimental study on bending and shear behaviours of composite timber sandwich panels. Construction and Building Materials, 259(4), 119723. DOI 10.1016/j.conbuildmat.2020.119723.

26. Williams, J. G. (1988). On the calculation of energy release rates for cracked laminates. International Journal of Fracture, 36(2), 101-119. DOI 10.1007/BF00017790.

27. Wang, C. Y., Zhang, X. K., Liu, Y. L. (2021). Experimental study on fracture patterns and crack propagation of sandstone based on acoustic emission. Advances in Civil Engineering, 4, 1-13. DOI 10.1155 / 2021/8847158.

28. Low, I. M., Che, Z. Y., Latella, B. A., Sim, K. S. (2006). Mechanical and fracture properties of bamboo. Key Engineering Materials, 312, 15-20. DOI 10.4028/www.scientific.net/KEM.312.15.

29. Oz, F. E., Ahmadvashaghbash, S., Ersoy, N. (2019). Damage mode identification in transverse crack tension specimens using acoustic emission and correlation with finite element progressive damage model. Composites Part B: Engineering, 165, 84-95. DOI 10.1016/j.compositesb.2018.11.104.

30. Wu, W. Q., Chen, S., Ma, X. Y. (2012). Test research on flexural and shear properties of bamboo plywood. Applied Mechanics and Materials, 1799, 2951-2957. DOI 10.4028/www.scientific.net/AMM.166-169.2951.

31. Chen, G. W., Luo, H. Y. (2021). Asymmetric flexural process and fracture behaviors of natural bamboo node with gradient discontinuous fibers. Composites Communications, 24, 100647. DOI 10.1016/j.coco.2021.100647. 